\title{
Human Nature: the Foundation of Politics and Law
}

\author{
Yue Yang \\ Guangzhou 510425, China \\ E-mail: yyllqq2007@163.com
}

\begin{abstract}
To study the human nature is the most important project for human knowing themselves. Human being has thought and probed into the problem of human nature since the naissance. Unfortunately, although modern human has already achieved great processes and marvelous successes in natural science, the recognition to human nature is superficial. All descriptions about human nature past and now focus on the surface of the problem instead of the essence. This paper points out the puzzle of human nature. By analyzing and illustrating the characteristics of human nature, this paper chiefly discusses the social effect of human nature in perspective of politics and laws. Finally, this paper examines the real world with defects, where the common human nature is ignorant.
\end{abstract}

Keywords: Human nature, Politics, Law, Humanities and social sciences

To study the human nature is the most important project for human knowing themselves. Human being has thought and probed into the problem of human nature since the naissance. Unfortunately, although modern human has already achieved great processes and marvelous successes in natural science, the recognition to human nature is superficial. All descriptions about human nature past and now focus on the surface of the problem instead of the essence. For human being, "to know self" is the most difficult problem. "Human nature is an unsolvable project. Human nature is fixed in a sense. There is certain law. However, it is complex and changeable and hard to be known. (Lixun Xie, 2006, p1)" Individuals and human do not recognize the self really. Human social progresses need to find and improve human nature. Human social progresses are based on human nature's discovery and improvement.

The potential and unknown meaning is that human nature is the most essential factor in all humanism and social phenomena. "In order to understand problems of human, we must know the human nature exactly and comprehensively. (Xiongshan Tang, 2007, p1)" Without human nature, there is no human society. Without human nature, earth will be an animal world forever. Human nature is a unique and special flag for human society in the universe. Human nature and politics, human nature and law, human nature and economy, human nature and education, human nature and science, human nature and culture, human nature and ethics, human nature and groups (families, parties, and nations), human nature and war, human nature and history, ...... human nature is the key for opening the door of all humanism and social knowledge. All humanism knowledge is about human nature in essence. All social problems are about human nature in nature.

\section{The puzzle of human nature}

Although humanization has turned into a fashionable slogan and even become a universal world value standard for dealing with humanism and social affairs, nobody know what human nature is exactly. In contrast to human's recognition to the nature, the recognition to human nature is still in a puzzle. In the humanism social science field, human nature does not attract sufficient attentions now. In history, almost no famous thinker or theorist takes human nature as an independent and important project in research. Thinkers and theorists who probe into the essence and laws of human society do not constitute a special and mature branch of human nature. In the ocean of knowledge, there is no widely accepted and influencing theoretical system concerning human nature. The top special research on human nature is that David Hume combines human nature and ethical morals together: "No matter how dull and unpleasant the abstract discussions over human nature are, they benefit practical ethics science. Besides, they can make practical ethics science be more exacter and convincible. (David Hume, ?, p1267)"

Limited recognitions to human nature are full of rooted misunderstandings and bias. From the past to now, the most popular view is on good and evil of human nature. "On Good and Evil" does not offer a detailed, specific, and clear description of human nature. The truth of human nature is not only either good or evil. "On Good and Evil" is limited in reflecting human nature. It does not grasp the essence of human nature. To classify human into the good and the evil according to the standards for good or evil of human nature is naive. Even if we use the standards to evaluate human, seldom people are either the good or the evil. Most are medium. Social conflicts and contradictions are not simply caused by the conflicts and contradictions between the good and the evil. Real conditions are more complicated. Conflicts and contradictions happen between the good and the evil, the good and the medium, the medium and the evil, the good and the good, the evil and the evil, the medium and the medium. Therefore, we can conclude that social 
conflicts and contradictions are not caused by the opposite of the good and the evil to a great degree.

From another angle, "On Good and Evil" takes human nature as simple. It agrees that human nature is composed by pure good and pure evil. As a matter of fact, similar to plants' resistance and toxicity, human nature's good and evil is complex and comprehensive and not simple. Plants' resistance and toxicity is determined by complicated chemical components and molecular structure. Human nature's good and evil is determined by complex psychological components and quality structure.

\section{The characteristics of human nature}

Characteristics of human nature are special marks that distinguishing human from other things. Human being is the most complicated system in the universe. Human is composed of two parts: physiological part as hardware attribute, namely the constitution; psychological part as software attribute, namely the human nature. Therefore, human nature is a systematic attribute of human. Human nature has a systematic level structure. It is in a dynamic and systematic evolvement process.

Human nature has certain structure and special mechanism. We can study human nature by anatomy. To describe the human nature is necessary but it is insufficient. To study and recognize human nature is beyond descriptions, even it is a vivid description. It needs fundamental abstract and analysis. Only by abstract and analysis, we can touch the essence and the truth of human nature.

The basic characteristics of human nature include: according to the evolvement process, human nature is sorted into primary human nature and senior human nature; according to the components and structure, human nature is sorted into basic human nature and complex human nature; the basic dimension of human nature is: reason attribute, will attribute, and affection attribute; the basic internal relationship of human nature is: the relationship between reason and affection, the relationship between reason and will, and the relationship between will and affection. More specific characteristics of human nature are displayed as follow.

Reason ------ Human nature takes reason as the core component. Reason is a belief of exploring, holding, and following the truth and the thinking based on scientific analysis, recognition, and decision. Human evolvement is the next step of biological evolvement. Its core is an evolvement of reason, from primary human nature to senior human nature, from free human nature to self-conscious human nature, from animal wild nature to human reason.

Non-reason ------ impurities of human nature, such as blindness, prejudice, violence, self-indulgence, peremptoriness, sinner, jealousness, suspicious, and cruel.

Knowability ------ Human nature is knowable. It can be observed and known. Although it is unclear, we can make abstract and analyze it as an object, and get useful knowledge.

Hierarchy ------ Human nature has two levels, namely the natural attribute and the social attribute. For human being, the natural attribute is the primary and initial human nature. The social attribute is an advanced human nature. For individuals, the natural attribute is inborn and intrinsic human nature. The social attribute is based on acquired and learning human nature.

Polarization ------ Human nature has two opposite directions. For example, two poles with valuation: the positive human nature is rational, active, healthy, true, good, beautiful, and laborious; the negative human nature is irrational, negative, ill, false, evil, ugly, and lazy. Two poles without valuation: domination and execution, guidance and submissiveness.

Dualism ------ Human nature is different due various roles and situations. In social affairs, human is the participator and the bystander. In psychological activities, human is the subject and the object. It means a dual human nature.

Diversity ------ Human nature is diversified and not single. Human nature may be noble or inferior, pure or dirty, sincere or mean, laborious or lazy, genuine or false, kind or evil, beautiful or ugly, ......

Asymmetry ------ Every individual and group, as the participator or the bystander, the subject or the object, has different human nature in perspective of sensitivity and intensity. Human nature's asymmetry is similar to the asymmetric input and output of semiconductor. In many circumstances, the asymmetry of human nature is the root for interpersonal conflicts.

Complexity ------ Human nature is composed of multi-dimensional elements by following certain structure, which gives human nature different forms.

Changeability ----- Human nature can be changed. Two ways can change human nature. One is natural evolvement. The other is self-shaping. Changes of human nature follow two mechanisms. One is dependent mechanism, in which human nature changes due to exterior influences and effects. The other is independent mechanism, in which human nature changes due to internal influences and effects.

Interactivity ------ Mutual effects happen in interpersonal interaction, which serve as the base for mutual relationship of 
human. Human nature's interactivity is sorted into positive interactivity and negative interactivity.

Consciousness ------ Under the effect of reason, human nature can achieve self consciousness and self awareness, which signalizes the evolvement and progress of human nature. The consciousness degree of human nature is one of factors determining human civilization.

From a wider point of view, we can identify some healthy characteristics of human nature, such as coordination, tolerance, politeness, dominance (include self dominance and other dominance), sincerity, honesty, coziness, restraint, independence, competitiveness, and subjective relativity, and some ill characteristics of human nature, such as cruelty, cheat, false, blindness, lazy, sinner, narrowness, cruelty, adherence, and parasitic. All these characteristics deserve to be studied further.

\section{Appearances of human nature}

No matter what it is domestic politics or international politics, domestic law or international law, the definition of relationship and right or wrong depend on human nature. Human nature covers the whole human behavioral cycle. Human behavioral cycle includes target $\rightarrow$ perception $\rightarrow$ judge $\rightarrow$ decision $\rightarrow$ activity $\rightarrow$ feedback. To enhance and maintain interests is the main principle of establishing the target. Interpersonal relationship concerns all participators' behavioral cycles. Whether targets are in coordination and other rings are in coordination determine whether the interpersonal relationship is in harmony. The divergence of targets mainly reflects people's competition for interests. In political affairs and legal businesses, people usually think that interpersonal conflicts and contradictions are caused by competition for interests, which mainly concerns the occupation of resources and the distribution of rights and wealth. As a matter of fact, except for that point, amounts of interpersonal contradictions and conflicts are not caused by interest-related factors but non-interest-related factors. In human behavioral cycle, the appearances of human nature are multi-dimensional. Any dimension may turn into the inducement of interpersonal contradictions and conflicts, such as suspicious, misunderstanding, illusion, bias, prejudice, peacockery, jealousness, sinner, and ignorance. All these dimensions may cause or deepen interpersonal contradictions and conflicts. Differences in some good aspects, such as habit, tradition, interest, opinion, and hobby, also play roles of arousing interpersonal contradictions and conflicts in colorful social life.

Social contradiction and social conflict are not completely, sometimes are not mainly interest contradiction and interest conflict. As interests are in consistent, lots of contradictions and conflicts, and even serious ones happen among people. In families, nations and sorts of social units, family members and national parties have common interests. All members may hope to maintain and strengthen the common interests. Unfortunately, facts are on the opposite. People who try to sustain and strengthen the common interests fall in conflicts frequently. As a result, all kinds of tragedies are popular in the world from the past to now. Surely, some social members may position self interests at the opposite of others and even give self interests higher priorities. This kind of pure interest conflicts and contradictions are common. However, people may neglect the contradictions and conflicts caused by common interests. This phenomenon should be noticed to a great degree. Parties that fall in conflicts and contradictions for common interests claim that they are representatives of common interests. They have the just reason, the right motive, and the unchangeable will. Therefore, this kind of conflicts and contradictions can not be solved by balancing interests.

For some contradictions and conflicts, things go contrary to wishes. In the society, social members have the same interests with others. Subjectively, they would not like to benefit themselves by hurting others. In fact, they want to benefit both themselves and others. One social member always thinks for others, makes decision for others, orders others, and directs others. In his or her mind, he or she is for others' interests. However, in practical life, contradictions and conflicts between he or she with others happen frequently. They can not live in harmony. The negative effect of mutual relationship is accumulated gradually. For certain serious circumstance, it may hurt oneself and some people for the sake of the other's interests. Even if he or she has the kind motive and even if he or she has the right, the responsibility, and the obligation to help others, he or she should impose self wills and wishes on others. People with high human nature qualities and consciousness can care for others and respect others' wills at the same time. Then, they can get others' understandings and cooperation, avoiding contradictions and conflicts with others.

Individuals' human nature appearances are similar to nations' human nature appearances. To analyze the non-interest factors of interpersonal contradictions and conflicts, we should emphasize on improving the non-interest factors' human nature appearances, preventing, avoiding, and excluding suspicious, misunderstanding, illusion, bias, prejudice, peacockery, jealousness, lazy, sinner, and ignorance. Tolerant and respect others' habits, traditions, interests, opinions, and hobbies, which can help to adjust and dissolve interpersonal contradictions and conflicts in a social micro aspect and national contradictions and conflicts in a social macro aspect.

\section{Effects of human nature}

All beautiful things and affairs are originated from effects of human nature. So do all ugly things and affairs. Human nature is the ultimate root of all social contradictions and conflicts. Politics and law are results from social 
contradictions on one hand. On the other hand, as basic institutions, they are used to adjust social contradictions and stabilize social orders by taking powers and rules as methods. Therefore, according to the progressive relationship from human nature to social contradictions to politics and law, social contradictions are nothing but a medium. Human nature is the logic starting point of politics and law. Human nature needs are the basis for the construction of politics and law. Politics and law are results of human rationality. But they also have irrational components. Fair and just politics and law have restraint effects, adjustment effects, buffer effects, transmission effect, and chain effects on social relationship based on human nature. The ideal goal of politics and law reflects human nature's desire. The essence of equality is the equality of human nature. The essence of freedom is also the freedom of human nature. Originally, the evolvement of human nature determines the civilizing progress of politics and law.

Human nature is the ring of all social relationship. Political relationship and legal relationship are also knitted by human nature. Every political relationship maintains the human nature of people's political status. Every legal relationship maintains the human nature of people's legal status. Therefore, the essence and the core of social relationship is the relation of human nature. The social relationship between one person with another person, one group with another group is the relationship between one person's human nature with another's, and one group's human nature with another's.

Interpersonal relationship, in content or in form, is the contact reflection and the mutual effect of human nature. It is maybe compatible or repellent. Under the common circumstance, the compatible effect merely accounts for one fourth. Only when A's positive human nature contacts with B's positive human nature, can it exert compatible effects. For other three conditions, A's positive human nature and B's negative human nature, B's positive human nature and A's negative human nature, A's negative human nature and B's negative human nature, repellent effects happen. From another angle, the contact effect of human nature is maybe communication or impact. Human nature's repellent effect and impact are causes for kinds of social contradictions and conflicts. Conflicts of human nature are the essence of all political and legal disputes.

The adjustment of politics and laws for social relationship finally result in human nature. Consequently, it benefits some people's human nature and restricts others'; indulges some people's human nature and suppresses others'; protects some people's human nature and reshape others'. In perspective of human nature, the social system has two extreme modes. In one mode, the mechanism of politics and law is based on social common interests. Meanwhile, politics and law are used to regulate and restrict personalities, which may suppress and kill personalities. In the other mode, the mechanism of politics and law is based on social members' free personalities. Meanwhile, politics and law are used to pursue for social common interests. Sometimes, it may hurt social common interests.

There are three kinds of mutual effects among human nature, politics, and law. Human nature has a unidirectional effect on politics and law. Politics and law have a unidirectional reaction on human nature. There is a bilateral alternate effect between human nature and politics and law. In practice, human nature is the backbone of politics and law. In academy, the position and effect of the science of human nature in humanism and social sciences is similar to the position and effect of physics and chemistry in natural sciences. The science of human nature should be the fundamental subject in humanism and social sciences. Therefore, studies of political and legal issues should be combined with researches on human nature. The perfection of political system and legal system should integrate with the perfection of human nature.

\section{Conclusion}

In the evolvement of human nature, what observers see from the past to now is: the ignorance, disability, and shortcomings of human nature are world-wide and global. The imperfection and insufficiency of human civilization are also world-wide and global. The shortcomings and defects of social politics and legal system are more world-wide and global. The so-called civilization and culture differences between the west and the east are superficial but not in nature. So do the differences of social politics and legal system.

The most sensitive political and legal issue is about democracy and human right. Conditions of democracy and human right are terrible globally. Parties in disputing for democracy or pseudo democracy are in an imperfect democratic system. In countries that claim for democracy, the illusion of democracy is more than practice. Similarly, in countries that claim for human right, phenomena of invading human rights are popular. No country supports anti-democracy or anti-human right in the flag. No country carries out pure democracy and respects human right really. In the uncertain future, "as the development of sciences of human nature and human relationships catches up with the development of sciences of nature and materials, what they care about will be how to change human nature effectively. (John Dewey, 2006, p164)" Only when substantial progresses have been achieved in fields of recognizing and improving human nature, can an ideal society for human spiritual life be actualized, just as human being step into an ideal material society after realizing the substantial progresses in recognizing and changing the nature. In the future, the hope lies in recognizing and changing human nature, similar to recognizing and changing the nature.

In rationality, people who are pursuing for and dedicated to the ideal society are living at a wrong time. If human being 
has a common ideal society, we can get this conclusion: today the distance from the ideal society in recognition is infinite $(\infty)$, and the distance from the ideal society in practice is two times of infinity $(2 \infty)$. Therefore, today the world is still in a lagged-behind civilization and low development. It is the common dilemma and tragedy of human being. In the world, although few people feel happy and lucky, it is based on most people's pains, unhappiness, and sadness. The process of human identifying and overcoming negative human nature, understanding and cultivating positive human nature is maybe as long as the geological age and the astronomical distance.

\section{References}

David Hume. A Treatise of Human Nature. Beijing: Jiuzhou Publishing House. p1267.

John Dewey. Translated by Fu, Tongxian. (2006). Problems of Men. Shanghai: Shanghai People's Publishing House. June. p164.

Tang, Xiongshan. (2007). Balance Theory of Human Nature. Guangzhou: Sun Yat-Sen University Press. Mar. p1. Xie, Lixun. (2006). On Human Nature. Changsha: Hunan People’s Publishing House. Dec. p1. 